\section{Modeling mutations in the $\mathbf{G}_{1}$ arrest pathway in human gliomas: overexpression of CDK 4 but not loss of IN K 4a- ARF induces hyperploidy in cultured mouse astrocytes}

\author{
Eric C. Holland, ${ }^{1,3}$ Wendy P. Hively, ${ }^{1}$ \\ Vittorio Gallo, ${ }^{2}$ and Harold E. Varmus ${ }^{1}$ \\ ${ }^{1}$ Division of Basic Sciences, $\mathrm{N}$ ational Cancer Institute, \\ ${ }^{2}$ Laboratory of Cellular and $\mathrm{M}$ olecular N europhysiology, \\ N ational Institute of Child Heal th and Human Development, \\ $\mathrm{N}$ ational Institutes of Health, Bethesda, M aryland 20892 USA
}

\begin{abstract}
Neary all human gliomas exhibit alterations in one of three genetic loci governing $G_{1}$ arrest: INK4a-ARF, CDK 4, or RB. To discem the roles of CDK4 amplifica tion and INK4a-ARF loss in gliomagenesis, we compared the behavior of astrocytes lacking a functional IN K 4a-ARF locus with astrocytes overexpressing CD K 4. Either a deficiency of $\mathrm{p} 16^{\mathrm{INK} 4 \mathrm{a}}$ and $\mathrm{p} 19^{\mathrm{ARF}}$ or an increase in Colk4 allows cultured astrocytes to grow without senescence Astrocytes overexpressing CDK4 grow more slowly than IN K 4a-ARF-deficient astrocytes and convert to a tetraploid state at high efficiency; in contrast, IN K 4a-AR F-deficient cells remain pseudodiploid, consistent with properties observed in human gliomas with corresponding lesions in these genes.
\end{abstract}

Received July 20, 1998; revised version accepted October 14, 1998.

Over half of high-grade human gliomas lack a functional INK4a-ARF locus (Jen et al. 1994; Schmidt et al. 1994) and hence can produce neither p16 IN K4a nor p19ARF, the two proteins encoded by this locus (Quelle et al. 1995). M ost of the remai ning gl iomas either lack the RB gene or demonstrate a 10- to 100-fold amplification of the CDK4 locus (He et al. 1994, 1995; Ichimura et al. 1996). We are developing animal models for gliomagenesis in hopes of understanding these patterns and discerning the contributions made to tumor formation by each abnormality (Holland et al. 1998). We have taken advantage of two genetic alterations in mice: disruption of the INK4aARF locus by targeted mutation (Serrano et al . 1996) and astrocyte-specific expression of a transgene encoding TVA, the receptor for subgroup $A$ avian leukosis viruses (ALV) (Holland and Varmus 1998). Production of TVA molecules by these cells makes them susceptible to in-

[Key Words: $\mathrm{G}_{1}$ arrest; CDK4 amplification; INK4a-ARF Ioss; gliomagenesis; mouse astrocytes]

${ }^{3}$ Corresponding author. Present address: Departments of Neurosurgery and Molecular Genetics, M.D. Anderson Cancer Center, Houston, Texas 77030 USA.

E-MAIL eholland@notes.mdacc.tmc.edu; FAX (713) 794-4950. fection by RCAS vectors carrying coding domains for CDK 4 and other genes (Holland et al. 1998).

We have used this gene transfer system to investi gate the effects of INK4a-ARF loss and CDK4 overexpression in astrocyte cell culture and to determine whether similarities exist between the cultured cells and human gliomas with similar abnormalities.

\section{Results and Discussion}

Loss of IN K4a-ARF and overexpression of CDK4 both immortal ize astrocyte cultures

To compare the growth properties of INK4a-ARF-deficient and CDK4-overexpressing astrocytes, we subjected appropriately selected cultures to repeated passage at standard density and counted the number of cells at each passage. Astrocytes overexpressing CDK4 were prepared by infecting primary brain cultures from Gtv-a mice [carrying a tv-a transgene under the control of the astrocytespecific glial fibrillary acidic protein (GFAP) promoter] with an RCAS vector carrying the human CDK4 CDNA (RCAS-cdk4). Cultures of INK4a-ARF-deficient astrocytes were prepared by infecting primary brain cell cultures from Gtv-a transgenic; INK4a-ARF ${ }^{-1-}$ mice with an RCAS vector bearing the puro-R gene (RCAS-puro) (Holland et al. 1998) and selecting for resistance to puromycin. Parallel cultures were prepared by infecting brain cells from Gtv-a transgenic mice with RCAS vectors carrying the alkaline phosphatase (AP) or the basic fibroblast growth factor (bFGF) coding sequences.

As ill ustrated in Figure 1A, control astrocytes underwent about three or four cell doublings, gradually entered senescence, and failed to survive beyond $\sim 50$ days. Astrocytes infected with RCAS-bFGF, which induce proliferation and migration of glial cells in vivo (Holland and Varmus 1998; also see Fig. 4, below), grew to slightly greater numbers than control astrocytes, as expected in view of the known mitogenic effects of bFGF on cultured astrocytes (Hou et al. 1995) but did not survive significantly longer. In marked contrast, INK4a-ARF ${ }^{-1}$ astrocytes exhibited no loss of growth potential with passage and could be propagated indefinitely, consistent with the behavior of mouse embryo fibroblasts (MEFs) with lesions in this locus (Alcorta et al. 1996; N obel et al. 1996) or in ARF al one (Kamijo et al. 1997). Furthermore, astrocytes infected with RCAS-cdk4 al so escaped senescence, implying that both INK4a-ARF deficiency and excess CDK4 allow immortalization of astrocytes. However, the growth rates for these two populations were markedly different; INK4a-ARF ${ }^{-1-}$ cultures grew at a rapid and constant rate, whereas the CDK4-immortal ized cultures initially grew slowly and then increased in rate over time.

We demonstrated that the INK4a-ARF ${ }^{-1-}$ and CDK4immortalized cultures were glia by staining cells with antibodies to GFAP (Bignami and Dahl 1976) and to nestin, an intermediate filament protein expressed in CNS progenitors (Tohyama et al. 1992). Gtv-a transgenic pri- 

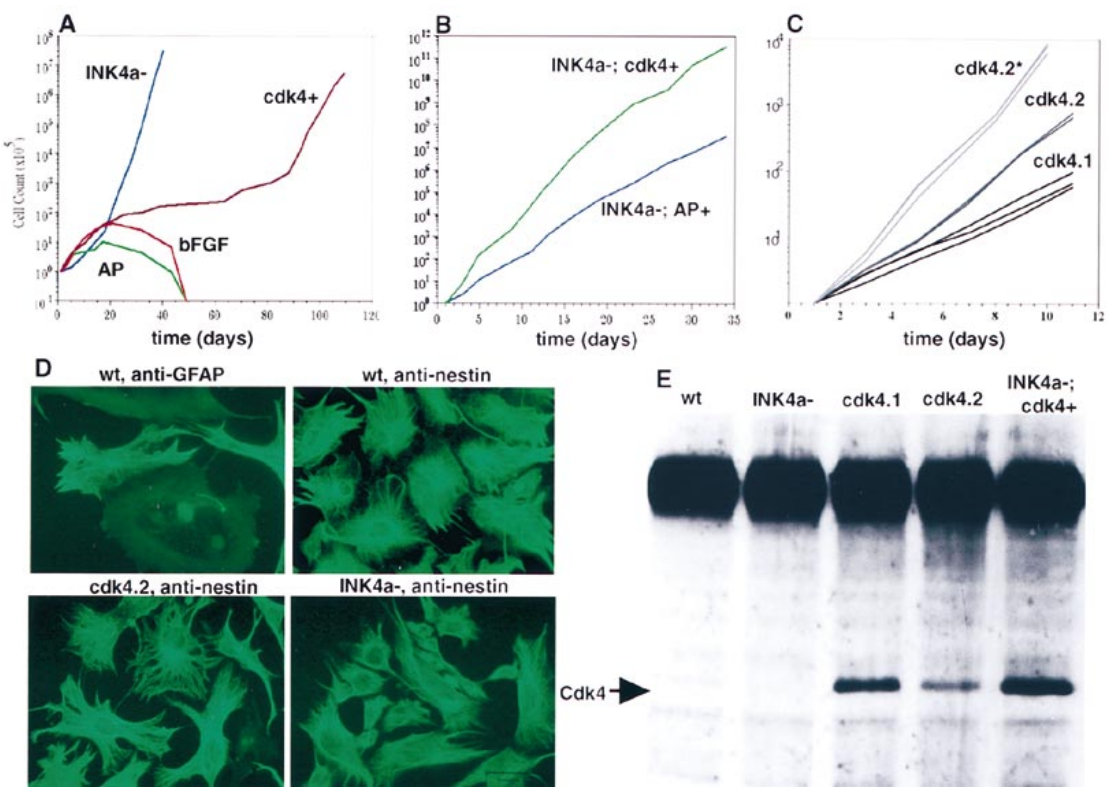

Figure 1. Immortalization of astrocytes by INK4a-ARF loss and cdk4 overexpression. (A) Growth curves comparing INK4a-ARF ${ }^{-1-}$ astrocytes (IN K4a-) with wild-type tv-a+ astrocytes infected with RCAS-CDK4 $\left(\mathrm{cdk}^{+}\right), \mathrm{RCAS}-\mathrm{bFGF}\left(\mathrm{bFGF}^{+}\right)$, and RCAS-AP (AP). (B) Comparison of growth rates between INK4a-ARF ${ }^{-1-}$ astrocytes infected with RCAS-AP (IN K4a-; AP+) and RCAS-CDK4 (IN K4a-; cdk4+). (C) Growth curves comparing two independent Gtv-a astrocyte populations infected with RCAS-CDK4 and maintained in culture for 3 months (cdk4.1 and cdk4.2) rel ative to the cdk4.2 population after continuous maintenance in culture for a total of 9 months (cdk4.2*). (D) Immunofluoresence staining for GFAP and nestin in INK4a-ARF ${ }^{+/+}$astrocytes. Anti-nestin immunofluoresence in cdk4 immortalized and INK4a-ARF ${ }^{-1-}$ astrocytes. Magnification, 100x (E) IP-Western blot analysis of cultured cells for expression of Cdk4. The arrow indicates the position of the 34-kD CDK4 gene product. (wt) Wild-type astrocytes; (cdk4.1, cdk4.2, IN K4a-; cdk4+) as above.

mary brain cultures infected with RCAS-puro initially demonstrated a significant percentage of $\mathrm{GFAP}^{+}$cells (Fig. 1D), and virtually all cells expressed nestin as has been observed previously in rat astrocyte cultures (Gallo and Armstrong 1995). To better quantify the population of cells initially infected with RCAS vectors, Gtv-a transgenic primary brain cultures were infected with RCAS-GFP, carrying the gene for green fluorescence protein and anal yzed for green fluorescence, GFAP, and nestin. All of the $\mathrm{GFP}^{+}$cells were nestin-positive (data not shown). Importantly, $90 \%$ of the $\mathrm{GFP}^{+}$cells also expressed GFAP, as detected by immunocytochemistry and the remaining $10 \%$ of $\mathrm{GFP}^{+}$cells not expressing GFAP still displayed an astrocytic morphology. With continued passage, I NK4a-A RFF ${ }^{-1}$ and CDK4-immortalized cultures displayed a polygonal, flat morphology characteristic of cultured astrocytes and lost GFAP expression, as observed with astrocytes immortalized by other techniques (Bernard et al. 1994; Frisa et al. 1994). All cells in both populations expressed large amounts of nestin, consistent with a neuroectodermal origin (Frederiksen and McKay 1988). Very large nestin-positive cells were found in both the wild-type and colk4-immortalized populations; in contrast, the INK4a-ARF ${ }^{-1}$ cells were primarily small and morphologically immature.

The concentration of Cdk4 in RCAS-cdk4-immortal- ized astrocytes maintained for 3 months in culture was $\sim 5$ - to 10-fold higher than in wild-type astrocytes (Fig. 1D). These astrocytes grew less rapidly than INK4a-ARF ${ }^{-1}$ - cells, raising the possibility that excess $\mathrm{Cdk} 4$ is a less potent stimulator of growth than a combined deficiency of p19ARF and $\mathrm{p} 16^{\mathrm{INK} 4 \mathrm{a}}$. Although we have been unable to examine astrocytes producing higher levels of Cdk4, we have asked whether the growth stimulation provided by excessive $\mathrm{Cdk} 4$ would occur in the absence of p19ARF and p16 ${ }^{\mathrm{INK} 4 \mathrm{a}}$. Cultures from brains of INK4a-ARF ${ }^{-1}$; Gtv-a transgenic mice were infected with RCAS-cdk4 and also produced $~ 10$-fold higher than normal levels of Cdk4 (Fig. 1E). These cells grew significantly faster than INK4a-ARF ${ }^{-1}$; Gtv-a control infected cells (Fig. 1B). Thus, the growth stimulus provided by CDK4 overexpression is limited by both the CDK4 concentration and the presence of the INK4aARF products.

\section{CDK4 overexpression induces hyperploidy that is IN K4a-ARF dependent}

Tumor cells, including glioma cells, often contain an abnormal number of chromosomes (Bigner and M ark 1984), and hyperploidy occurs when mechanisms for control of cell cycle progression have been disrupted (Tahanda et al. 1995). Therefore, we asked whether euploidy is maintained in cultured astrocytes with a defici ency of INK4aARF or an excess of Cdk4, and whether any abnormalities in ploidy are correlated with specific genetic mutations, as reported in human gliomas (van Meyel et al. 1994). Flow cytometry was used to assess DN A content in astrocytes with different passage histories after maintenance at confluence or after addition of nocodazole.

By these measures, six of six astrocyte cultures independently infected with RCAS-cdk4 were mostly converted to tetrapl oid status within 15-20 population doublings (PD), at a rate approaching $10 \%$ of cells per generation (Fig. 2A). After 25 PDs, virtually all CDK4expressing cells had twice the normal amount of DNA at confluence, and nearly half of the nocodazole-treated cells were arrested in $\mathrm{G}_{2} / \mathrm{M}$ with an $8 \mathrm{~N}$ DNA content (Fig. 2B). In sharp contrast, INK4a-ARF-deficient cells were very similar to wild-type astrocytes, even after $>50$ PDs. In nocodazole, a higher proportion of INK4a-ARFdeficient cells than wild-type cells were arrested in $\mathrm{G}_{2} /$ $\mathrm{M}$, but $<10 \%$ of the cells had an $8 \mathrm{~N}$ DNA content (Fig. $2 \mathrm{~B}$, right). These findings were confirmed by direct inspection of metaphase chromosomes (Fig. 2D); chromosome numbers in metaphase spreads from INK4a-ARF- 
Holland et al.

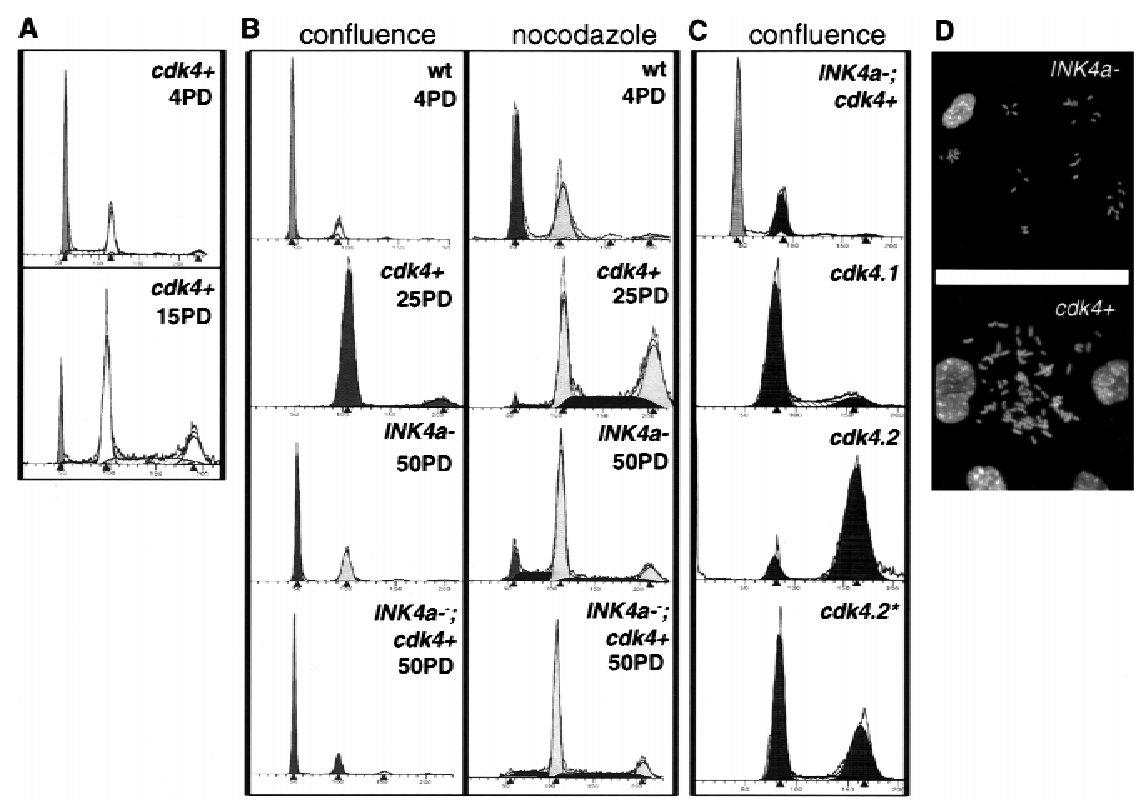

Figure 2. RCAS-cdk4-infected astrocytes shift to tetrapl oidy. Flow cytometry analysis of the indicated cultures after propidium iodide staining. (A) CDK4-Immortalized cells analyzed after 4 and 15 population doublings (PDs). (B) Cultures analyzed at confluence $\left(\mathrm{G}_{1}\right.$ arrest) after the indicated number of PDs and after treatment for $16 \mathrm{hr}$ with 0.12 $\mu \mathrm{g} / \mathrm{ml}$ nocodazole (right). (C) Flow cytometry of cell cultures at confluence illustrating the pseudodi pl oid RCAS-cdk4-infected INK4a-A $\mathrm{RF}^{-1-}$; Gtv-a astrocytes maintained for 9 months in culture compared with the hyperploid cdk4.1, cdk4.2, and cdk4.2* populations described above. (D) M etaphase spreads of di ploid INK4a-ARF ${ }^{-1-}$ and tetraploid CDK4-immortalized cells as indicated.

deficient cells were 40 and thus diploid or pseudodiploid, whereas CDK4-overexpressing cells had approximately twice the normal number of chromosomes.

The number of recognized genetic alterations capable of immortalizing cells in culture is relatively small; and of those, only loss of p53 function and hyperproduction of Myc protein have been reported previously to induce hyperploidy. The mechanism by which el evated levels of Cdk4 induce hyperploidy is unknown but in some way must result from endoduplication of chromosomes and aberrant cell cycle arrest in $\mathrm{G}_{2}$.

We next examined the DNA content of INK4a-ARF ${ }^{-1}$; Gtv-a astrocytes infected with RCAS-cdk4 and producing at least 10-fold more Cdk4 than normal cells (Fig. 1E). Surprisingly, these cells maintained pseudodiploidy, implying a requi rement for one or both of the products of the INK4a-ARF locus for induction of inappropriate rounds of DNA replication by Cdk4. p19ARF functions by binding to $\mathrm{Mdm} 2$ and thereby inactivating p53 (Kamijo et al. 1997; Pomerantz et al. 1998; Zhang et al. 1998) and is involved in both $G_{1}$ and $G_{2}$ arrest (Quelle et al . 1997). Therefore, it may be a more likely candidate to promote Cdk4-induced hyperploidy than $\mathrm{p} 16^{\mathrm{INK} 4 a}$, which is known only to inhibit $\mathrm{Cdk} 4$ and block passage from $\mathrm{G}_{1}$ to $\mathrm{S}$ phase. Overexpression of CDK4 in astrocytes derived from mice with targeted mutations specific for p16 $6^{\mathrm{INK} 4 \mathrm{a}}$ or p19 ${ }^{\mathrm{ARF}}$ would help identify the INK4a-ARF product required for $\mathrm{Cdk} 4$-induced hyperpl oidy.

Curiously, although mutations in p53 lead to aneu- ploidy in culture, a mutation that specifically el iminates the production of p19ARF results in pseudodiploid immortalized cells (Kamijo et al. 1997). It is not known whether the shift in ploidy seen in $\mathrm{p} 53^{-1-}$ cells is dependent on the presence of wild-type p19ARF or p16 iN K4a as appears to be the case for the ploidy shift due to cdk4 overexpression.

\section{Cdk4-induced immortalization and hyperploidy can occur independent of p53 mutations}

Mutations in $\mathrm{p} 53$ are associated with loss of growth control and chromosomal instability (Levine 1993). Thus, secondary mutations of p53 in astrocytes infected with RCAS-cdk4 could be responsible for the properties described above. To address this possibility we analyzed two independent populations of RCAS-cdk4-infected Gtv-a astrocytes that had been maintained in culture for 3 months. Both populations (cdk4.1 and cdk4.2) showed elevated levels of Cdk4 by Western analysis (Fig. 1D). Flow cytometry of these two populations (performed on day 6 of the experiment shown in Fig. 3) demonstrated that cdk4.1 cells are mostly tetraploid and cdk 4.2 cells mostly octaploid.

We judged p53 status using three criteria: immunohistochemical staining with antibodies specific for the mutant conformation of $\mathrm{p} 53$; the level of total $\mathrm{p} 53$ by Western blot analysis; and the induction of p21 after DNA damage. By all three criteria the cdk4.1 population showed no evidence of mutant p53 (Fig. 3). These data imply that in the cok4.1 culture, immortalization and hyperploidy occurred in the presence of wild-type p53 protein and normal p53 function.

The cdk4.2 culture, in contrast, stained positively with the antibody for the mutant p53 and failed to induce p21 after camptothecan treatment. The cdk4.2 population was mai ntained in culture for an additional 6 months (cdk4.2*) and analyzed for ploidy, growth rate, and p53 status. The cdk4.2* cells demonstrated increased growth rate relative to that seen at 3 months (Fig. 1C), maintained evidence of mutant p53 by immunocytochemical criteria, and lacked p21 induction after camptothecan treatment. Surprisingly, flow cytometry showed that the population shifted from being mainly octaploid at 3 months to mainly tetraploid at 9 months. Presumably, the increased growth rate observed between the cdk4.2 population after 6 additional months in culture reflects the further occurrence of mutations, epigenetic events, or both. 


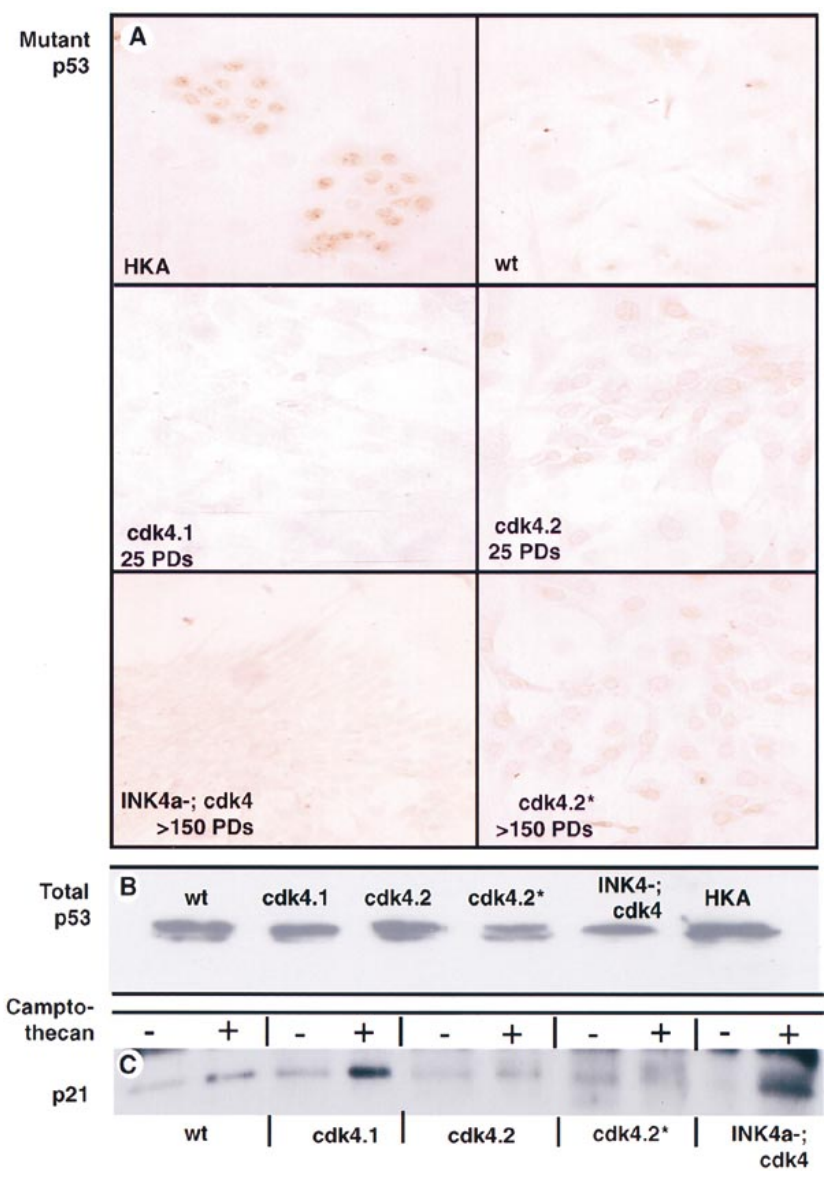

Figure 3. Mutations in p53 can, but do not necessarily, arise in CDK4-immortalized populations. (A) Immunoperoxidase staining of cell cultures using a monoclonal antibody to the mutant conformation of p53. Wild type, cdk4.1, cdk4.2, cdk4.2*, and INK4a-; $\mathrm{cdk}^{+}$are as in Fig. 1, (HKA) human keratinocyte cell line known to harbor a p53 mutation. (B) Western analysis for p53 in the indicated cultures. (C) Western analysis for p21 in cultured cells with and without camptothecan-induced DNA damage.

The existence of a CDK4-immortal ized and hyperploid culture with wild-typep53 function (cdk4.1) implies that CDK4-overexpressing astrocytes do not require mutations in p53 to achieve extended proliferation and genomic instability. The extended life span of the cdk4.1 population could be formally explained by a secondary mutation in INK4a-ARF or ARF al one. However, this is unlikely, as INK4a-ARF; CDK4-overexpressing astrocytes are pseudodiploid and rapidly proliferating, whereas the cdk4.1 population is polyploid and grows more slowly. Furthermore, Southern analysis of the cdk4.1 population with the p19ARF CDNA did not demonstrate deletions or alterations in the genomic structure of the INK4a-ARF locus (data not shown). These data imply that additional mutations in p53 or INK4aARF are not required for immortalization of CDK4-overexpressing astrocytes. In contrast, immortalization of MEFs by myc overexpression sel ects for those that lose either p53 or p19ARF function (Zindy et al. 1998) and
MEF cultures selected for spontaneous immortalization develop mutations in p53 or ARF (Kamijo et al. 1997). Although mutations in p53 have long been known to result in both immortalization of cells in culture and hyperploidy, the pathways leading to these effects are not compl etely understood. One of the effects of p53 is to increase the concentration of p21, which, in turn, inhibits Cdk4. Therefore, loss of p53 function might be expected to result in higher Cdk4 activity. It would be valuable to know whether the immortalization and pl oidy shifts seen in p53-deficient cells are a result of, or dependent on, inappropriately el evated Cdk4 activity.

O verexpression of cdk 4 by astrocytes in vivo does not induce proliferation

To gauge the physi ol ogi cal si gnificance of $\mathrm{Cdk} 4$ overproduction in astrocytes in vivo, we infected newborn Gtv-a transgenic mice with RCAS-cdk4. With this method, cells lining the injection track are coinfected with RCAS-AP to monitor cells (Holland and Varmus 1998). $\mathrm{AP}^{+}$cells are no more numerous or widely dispersed after coinfection with a mixture of RCAS-AP and RCAScdk4 than after infection with RCAS-AP alone (Fig. $4 \mathrm{~B}, \mathrm{C}$ ). In contrast, as described previously ( $\mathrm{Holland}$ and Varmus 1998), $\mathrm{AP}^{+}$cells are highly abundant and spread over a large expanse of the brain after coinfection with a mixture of RCAS-AP and RCAS-bFGF (Fig. 4A). Thus, by itself, excessive levels of Cdk4 do not appear to perturb the proliferative or migratory behavior of astrocytes in vivo.

The absence of gliomas in INK4a-A RF-deficient mice (Serrano et al. 1996) suggests that a lack of both p16 $6^{\text {IN K 4a }}$ and $\mathrm{p} 19^{\mathrm{ARF}}$ is insufficient to produce grossly abnormal growth of glial cells in vivo; this is similar to our results with gene transfer of cdk4 to astrocytes in Gtv-a transgenic mice (Fig. 4). However, either INK4a-ARF Ioss or CDK4 overexpression can immortalize astrocytes in vitro; thus, additional limitations on proliferation may be mediated by unknown mechanisms in vivo. Of note, cultures of both INK4a-A $\mathrm{RF}^{-1}$ and CDK4-immortalized cells arrest in $G_{1}$ upon reaching confluence, implying the
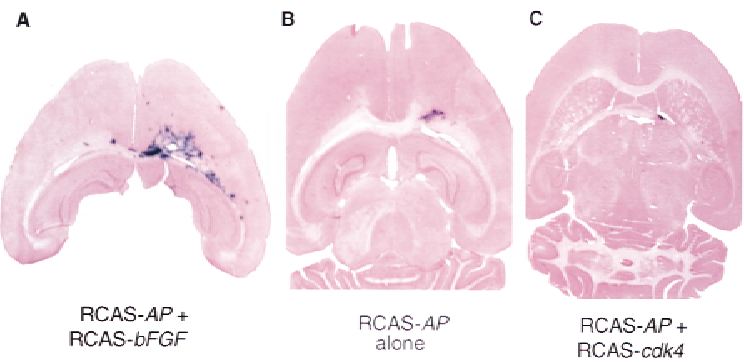

Figure 4. Glial-specific CDK4 gene transfer does not result in proliferation in vivo. An equal mixture of cells producing RCAS-AP and RCAS-bFGF (A), RCAS-AP al one (B), or RCAS$A P$ and RCAS-cdk4 (C) was injected into the right frontal lobe of Gtv-a mice. The mice were sacrificed and brains $(40-\mu$ sections) analyzed for AP activity at 10 weeks of age and counterstained. 
existence of an intact $\mathrm{G}_{1}$-arrest pathway in these cells. Identification of factors and pathways causing growth arrest of either INK4a-ARF ${ }^{-1-}$ or CDK4-immortalized astrocytes in culture may help elucidate the mechanism for arrest of these cells in vivo.

Recently, we have reported the utility of transgenes expressing tv-a in the glial lineage in intact animals (Holland and Varmus 1998; Holland et al. 1998). Here we demonstrate that primary cell lines from such tv-a transgenic animals can be used to perform high efficiency gene transfer to defined cells within a mixture of cell types. Selection for specific, infectable cell types is possible if the population is initially infected with RCASpuro and subsequently grown in puromycin. The ability to manipulate populations of primary astrocytes genetically in culture has allowed us to study the effects of individual alterations in the $G_{1}$ arrest pathways, something not possible in established cell lines in which the endogenous $\mathrm{G}_{1}$ arrest pathway has al ready been altered.

In Holland et al. (1998) we describe the contributions that excess Cdk4 or loss of the INK4a-ARF gene products make to gliomagenesis. We find that a constitutively active, mutant EGFR is insufficient to induce gliomas in mice, but mutant EGFR can induce glioma formation either in INK4a-ARF-1- mice or, less often, in combination with excess Cdk4. Furthermore, mutant EGFR does not induce gl iomas in p53-deficient mice unless CDK4 is overexpressed. Our results demonstrate that I NK4a-A RF Ioss and CDK4 overexpression not only immortalize astrocytes in culture, as shown here, but are also important components of gliomagenesis in mice. The fact that p53 mutations arise in some CDK4-immortalized astrocyte cultures implies that p53 loss can provide a growth advantage to these cells. The results in Holland et al. (1998) suggest that CDK4 overexpression and p53 loss also cooperate in gliomagenesis. These apparent interactions between components of the cell cycle arrest pathways in mice and in cultured mouse astrocytes resemble the genetic abnormalities found in human gliomas. M ost notably, results in the two species illustrate the importance of disrupting the p16 ${ }^{\mathrm{INK} 4 a_{-}}$ $\mathrm{Cdk} 4-\mathrm{Rb}$ pathway, the nonequivalence of mutations in the pathways that govern $\mathrm{G}_{1}-\mathrm{S}$ transition, and the apparent synergy between CDK4 overexpression and p53 loss. Taken as a whole, these observations indicate that behavior of genetically defined primary astrocyte cultures reflects many aspects of gliomagenesis both in mice and man.

\section{Materials and methods}

Transgenes and viral vectors

Construction of the Gtv-a transgene and RCAS-AP and RCAS-bFGF have been described (Holland and Varmus 1998). The Gtv-a mouse line was originally generated from an $\mathrm{FVB} / \mathrm{N}$ crossed with a C57B6 $\times \mathrm{BALB} / \mathrm{C}$ $F_{1}$. The Gtv-a founder was then bred to an FVB/N to generate $F_{1}$ progeny that have sunsequently been interbred to maintain the transgenic line. RCAS-puro was obtained from Steve Hughes ( $\mathrm{N}$ ational Cancer Institute). RCAS-cdk4 was constructed by Clal digestion of RCAS-puro to remove the Escherichia coli puromycin resistance gene and replacement with a BstBI-Clal fragment from pcdk4.1 (gift from Robert Sikorski), which contains the complete human CDK4 CDN A (M atsushime et al. 1992). RCAS-GFP was a gift of Connie Cepko (Harvard University, Cambridge, MA).
Cell culture

Primary brain cell cultures from newborn transgenic mice were obtained by mechanical dissociation of the whole brain, followed by digestion with $0.25 \%$ trypsin for $15 \mathrm{~min}$ at $37^{\circ} \mathrm{C}$. Large debris was al lowed to settle, and single cells were plated and grown in DMEM with 10\% FCS (GIBCO BRL). DF-1 cells (gift from D. Foster; Schaefer-Klein et al. 1998) were grown in DMEM with 5\% FCS, $5 \%$ calf serum, $1 \%$ chicken serum, and $10 \%$ tryptose phosphate broth (GIBCO BRL).

Infection with RCAS vectors

The supernatant from DF-1 cells infected with and producing RCAS vectors was filtered through a $0.45-\mu$ filter and plated directly onto primary brain cells cultures from Gtv-a mice. INK4a-ARF ${ }^{-1-}$; Gtv-a cultures were generated from the $F_{2}$ progeny of Gtv-a mated with mice having targeted del etions of INK4a-ARF (gift of Ron DePinho, Harvard M edical School, Boston, MA). These primary brain cultures were infected with filtered medium from RCAS-puro-producing cells and then selected in 4 $\mu \mathrm{g} / \mathrm{ml}$ puromycin. To infect cells in Gtv-a transgenic mice, DF-1 cells infected with RCAS vectors were harvested by trypsin digestion and pelleted by centrifugation, the cell pellets were resuspended in $\sim 50 \mu$ l of medium, and placed on ice. Using a $10-\mu l$ gas-tight Hamilton syringe, a single intracranial injection of $1 \mu$ l (containing $10^{4}$ cells) was made in the right frontal region, just anterior to the striatum, with the tip of the needle just touching the skull base.

Brain sectioning and staining

Animals were sacrificed at 10 weeks of age, the brains fixed in $4 \%$ formal dehyde, $0.4 \%$ glutaral dehyde, $1 \times$ PBS for $36 \mathrm{hr}$, and dehydrated in $20 \%$ sucrose, $2 \%$ glycerol, and $1 \times$ PBS. Frozen sections $(40 \mu \mathrm{m})$ were obtained using a sledge microtome (Zeiss) and stained in solution for alkaline phosphatase activity using 5-bromo-4-chl oro-indolyl-phosphate and 4-nitro-blue-tetrazolium-chloride (Boehringer), after treatment at $65^{\circ} \mathrm{C}(\mathrm{pH}$ 9.5) for $30 \mathrm{~min}$ to remove endogenous al kal ine phosphatase activity. The sections were then mounted on glass slides and counterstained with hematoxylin and eosin.

\section{Flow cytometry}

Cultures were either grown to confluence and maintained for $24 \mathrm{hr}$ or treated with $0.12 \mu \mathrm{g} / \mathrm{ml}$ nocodazole (Sigma) for $16 \mathrm{hr}$. Cells $\left(5 \times 10^{5}\right)$ were harvested by trypsin digestion, centrifuged, disbursed in $500 \mu \mathrm{l}$ of propidium iodide solution (Electa), incubated for $20 \mathrm{~min}$ at $37^{\circ} \mathrm{C}$, and analyzed on a Beckman FaxScan using M odFit LT software (Verity).

Immunofluorescence and immunohistochemistry

Cell cultures used for immunostaining were grown on glass coverslips precoated with $0.1 \mathrm{mg} / \mathrm{ml}$ poly-D-ornithine (Sigma). For staining with anti-GFAP antibodies, cells were fixed in 4\% paraformal dehyde $(\mathrm{pH} 7.4$ in PBS) for $15 \mathrm{~min}$, permeabilized in 95\% ethanol/5\% acetic acid for 10 min, and incubated with 1:300 diluted rabbit anti-human GFAP antibody (Chemicon) for $1 \mathrm{hr}$. After incubation with fluorescein- or rhodamineconjugated goat anti-rabbit (GAR; Cappel-Organon Teknika) for $45 \mathrm{~min}$, cells were washed extensively in PBS and mounted in Vectashield (Vector Laboratories). For staining with anti-nestin antibody, cells were fixed and permeabilized as described above and incubated overnight at $4{ }^{\circ} \mathrm{C}$ with an anti-nestin polyclonal rabbit antibody (gift from Ron McKay; Tohyama et al. 1992) (1:1000; in $1 \%$ fetal bovine serum $+0.5 \%$ bovine serum albumin). After incubation with fluorescein- or rhodamine-conjugated GAR for $45 \mathrm{~min}$ at room temperature, cells were washed extensively in PBS and mounted in Vectashield. The immunofluorescence micrographs presented are representative of two to three experiments and were taken on a Zeiss Axiophot fluorescence microscope $(40 \times \mathrm{N}$ eofluar objectives).

For detecting mutant p53, cells were initially fixed with $100 \%$ methanol and incubated with Tris-buffered saline ( $\mathrm{pH} 8.0), 0.1 \%$ Tween 20, (TBST) $5 \%$ dried milk, and $1 \%$ goat serum (TBST). A mouse monoclonal antibody recognizing mutant p53 in nondenaturing conditions (Ab-3, Oncogene Science) was incubated at a 1:200 concentration in TBST for $1 \mathrm{hr}$ at room temperature. The cells were washed with PBS and the antibody detected with a bi otin-conjugated anti-mouse antibody and avadin-horseradish peroxidase (ABC kit, Vector Labs).

Metaphase spread

Cells were treated with $0.02 \mathrm{mg} / \mathrm{ml}$ Colcemid (Sigma) for $6 \mathrm{hr}$ and harvested by trypsin digestion and centrifugation. The cells were resus- 
pended in $0.06 \mathrm{M} \mathrm{KCl}$, fixed in methanol/acetic acid (3:1), dropped onto glass slides, stained with $1 \mu \mathrm{g} / \mathrm{ml}$ DAPI (Polyscience), and visualized by fluorescence microscopy.

Western blot analysis

Total cell proteins $(0.6 \mathrm{mg})$ isolated in RIPA buffer were precipitated overnight at $4^{\circ} \mathrm{C}$ with $0.4 \mu \mathrm{g}$ of anti-C dk 4 antibody (Santa Cruz) using protein A-Sepharose (Sigma). The products were separated by SDS-PAGE and transferred to nitrocellulose. The blot was incubated with the same anti-Cdk4 antibody, washed extensively in TBST and incubated with a HRP-conjugated GAR antibody (Boehringer) and detected with ECL.

p21 was inducted by treating cultures at $70 \%$ confluence with $300 \mathrm{~nm}$ camptothecan (Sigma) for $24 \mathrm{hr}$. Total cellular protein was isolated in RIPA buffer, separated by SDS-PAGE transferred to nitrocellulose, and probed with p21 monoclonal antibodies (Ab-5, Calbiochem). The antibodies were visual ized using HRP-conjugated, anti-mouse antibody (Boehringer), and $\mathrm{ECL}$. For the p53 Western blot, total protein from untreated cultured cells was isolated and analyzed as for p21, using an anti-p53 antibody that recognizes both mutant and wild-type p53 proteins after denaturation under SDS-PAGE (Ab-3, Oncogene Science).

\section{Acknowledgments}

We thank Ron DePinho for the INK4a-ARF ${ }^{-1-}$ mouse line, Doug Foster for the DF-1 cells, Robert Sikorski for the CDK4 CDN A, Steve Hughes for RCAS-puro vector, Connie Cepko for RCAS-GFP vector, Ron M cKay for the anti-nestin antibody, Stacie Anderson for excellent assistance with the flow cytometry analysis, Zoe Weaver for expertise and help with the metaphase spread analysis, Bart Williams for many hel pful discussions, and Tony Wynshaw-Boris and $\mathrm{Yi}$ Li for critical reading of this manuscript. E.C.H. was a Howard Hughes Physician Postdoctoral Fellow.

The publication costs of this article were defrayed in part by payment of page charges. This article must therefore be hereby marked 'advertise ment' in accordance with 18 USC section 1734 solely to indicate this fact.

\section{References}

Alcorta, D.A., Y. Xiong, D. Phelps, D. Beach, and J.C. Barrett. 1996 Involvement of the cycline-dependent kinase inhibitor p16(IN K4a) in replicative senescence of normal human fibroblasts. Proc. Natl. Acad. Sci. 93: 13742-13747.

Bernard, R., M. LeBert, I. Borde, E. Galiana, C. Evrard, and P. Rouget. 1994. Immortalization of different precursors of glial cells with a targeted and temperature-sensitive oncogene. Exp. Cell Res. 214: $373-380$.

Bignami, A. and D. Dahl. 1976. The astroglial response to stabbing. Immunofluorescence studies with antibodies to astrocyte-specific protein (GFA) in mammalian and submammalian species. Neuropathol. Appl. Neurobiol. 2: 99-100.

Bigner, S.H. and J. Mark. 1984. Chromosomes and chromosomal progression of human gliomas in vivo, in vitro, and in athymic nude mice. Prog. Exp. Tumor Res. 27: 67-82.

Frederiksen, K. and R.D.G. McKay. 1988. Proliferation and differentiation of rat neuroepithelial precursor cells in vivo. J. Neurosci. 8: 1144-1151.

Frisa, P.S., M.N. Goodman, G.M. Smith, J. Silver, and J.W. Jacobberger. 1994. Immortalization of immature and mature mouse astrocytes with SV40 T antigen. J. Neurosci Res. 39: 47-56.

Gallo, V. and R.C. Armstrong. 1995. Developmental and growth factorinduced regulation of nestin in oligodendrocyte lineage cells. J. Neurosci. 15: 394-406.

He, J., J.R. Allen, V.P. Collins, M.J. Allalunis-Turner, R. Godbout, R.S. Day, and C.D. James. 1994. CDK4 amplification is an alternative mechanism to p16 gene homozygous deletion in gliomalines. Cancer Res. 54: 5804-5807.

He, J., J.J. Olson, and C.D. James. 1995. Lack of p16IN K4 or retinoblastoma protein $(\mathrm{pRb})$ or amplification-associated overexpression of cdk4 is observed in distinct subsets of mal ignant glial tumors and cell lines. Cancer Res. 55: 4833-4836.

Holland, E.C. and H.E. Varmus. 1998. Basic fibroblast growth factor induces cell migration and proliferation after glia-specific gene transfer in mice. Proc. Natl. Acad. Sci. 95: 1218-1223.
Holland, E.C., W.P. Hively, R.A. DePinho, and H.E. Varmus. 1998. A constitutively active epidermal growth factor receptor cooperates with disruption of $\mathrm{G}_{1}$ cell cycle arrest pathways to induce gl ioma-like lesions in mice. Genes \& Dev. (this issue).

Hou, Y.J., A.C.H. Yu, J.M .R.Z. Garcia, A. Aotaki-Keen, Y.L. Lee, L.F. Eng, L.J. Hjelmeland, and V.K. Menon. 1995. Astrogliosis in culture. IV. Effects of basic fibroblast growth factor. J. Neurosci. Res. 40: 359-370.

Ichimura, K., E.E. Schmidt, H.M. Goike, and V.P. Collins. 1996. Human gl ioblastomas with no al terations of the CDKN 2A (p16IN K4a, MTS1) and CDK 4 genes have frequent mutations of the retinoblastoma gene. Oncogene 13: 1065-1072.

Jen, J., J.W. Harper, S.H. Bigner, D.D. Bigner, N. Papadopoulos, S. Markowitz, J.K. Willson, K.W. Kinzler, and B. Vogelstein. 1994. De letion of p16 and p15 genes in brain tumors. Cancer Res. 54: 63536358.

Kamijo, T., F. Zindy, M.F. Roussel, D.E. Quelle, J.R. Dowling, R.A. Ashmun, G. Grosveld, and C.J. Sherr. 1997. Tumor suppression at the mouse IN K 4a locus mediated by the alternative reading frame product p19ARF. Cell 91: 649-659.

Levine, A.J. 1993. The tumor suppressor genes. Annu. Rev. Biochem. 62: 623-651.

M atsushime, H., M .E. Ewen, D.K. Strom, J. Kato, S.K. Hanks, M .F. Roussel, and C.J. Sherr. 1992. Identification and properties of an atypical catalytic subunit (p34PSK-J3/cdk4) for mammalian D type G1 cyclins. Cell 71: 323-334.

Nobel, J.R., E.M. Rogan, A.A. N eumann, K. Maclean, T.M. Bryan, and R.R. Reddel. 1996. Association of extended in vitro proliferative potential with loss of p16IN K4 expression. Oncogene 13: 1259-1268.

Pomerantz, J., N . Schreiber-Agus, N .J. Liegeois, A. Silverman, L. Alland, L. Chin, J. Potes, K. Chen, I. Orlow, H. Lee, C. Cordon-Cardo, and R.A. DePinho. 1998. The IN K4a tumor suppressor gene product, p19ARF, interacts with MDM 2 and neutralizes M DM 2's inhibition of p53. Cell 92: 713-723.

Quelle, D.E., F. Zindy, R.A. Ashmun, and C.J. Sherr. 1995. Alternative reading frames of the INK4a tumor suppressor gene encoding two unrelated proteins capable of inducing cell cycle arrest. Cell 83: 9931000.

Quelle, D.E., M. Cheng, R.A. Ashmun, and C.J. Sherr. 1997. Cancerassociated mutations at the IN K4a locus cancel cell cycle arrest by p16IN K4a but not by the alternative reading frame protein p19ARF. Proc. Natl. Acad. Sci. 94: 669-673.

Schaefer-Klein, J., I. Givol, E.V. Barsov, J.M. Witcomb, M. VanBrocklin, D.N. Foster, M.J. Federspiel, and S.H. Hughes. 1998 The EV-O-derived cell line DF-1 supports the efficient replication of avian leukosis-sarcoma viruses and vectors. Virology 248: 305-311.

Schmidt, E.E., K. Ichimura, G. Reifenberger, and V.P. Collins. 1994. CDKN 2 (p16/MTS1) gene deletion or cdk 4 amplification occurs in the majority of glioblastomas. Cancer Res. 54: 6321-6324.

Serrano, M., H. Lee, L. Chin, C. Cordon-Cardo, D. Beach, and R.A. DePinho. 1996. Role of the IN K4a locus in tumor suppression and cell motility. Cell 85: 27-37.

Tahanda, A.M., J.M. Bruner, L.A. Donehower, and R.S. Morrison. 1995. Astrocytes derived from p53-deficient mice provide a multistep in vitro model for development of malignant gliomas. Mol. Cell. Biol. 15: 4249-4259.

Tohyama, T., V. Lee, L.B. Rorke, M. Marvikn, R.D. McKay, and J.Q. Trojanowski. 1992. N estin expression in embryonic human neuroepithelium and in human neuroepithelial tumors. Lab. Invest. 66: 303-313.

van M eyel, D.J., D.A. Ransay, A.G. Casson, M. Keeney, A.F. Chambers, and J.G. Cairncross. 1994. p53 mutation, expression and DN A ploidy in evolving gliomas: evidence for two pathways of progression. J. Natl. Cancer Inst. 86: 1011-1017.

Zhang, Y., Y. Xiong, and W.G. Yarbrough. 1998. ARF promotes MDM 2 degradation and stabilizes p53: ARF-INK4a locus deletion impairs both the Rb and p53 tumor suppression pathways. Cell 92: 725-734.

Zindy, F., C.M. Eischen, D.H. Randle, T. Kamijo, J.L. Cleveland, C.J. Sherr, and M.F. Roussel. 1998. Myc signaling via the ARF tumor suppressor regulates $\mathrm{p} 53$-dependent apoptosis and immortalization. Genes \& Dev. 12: 2424-2433. 


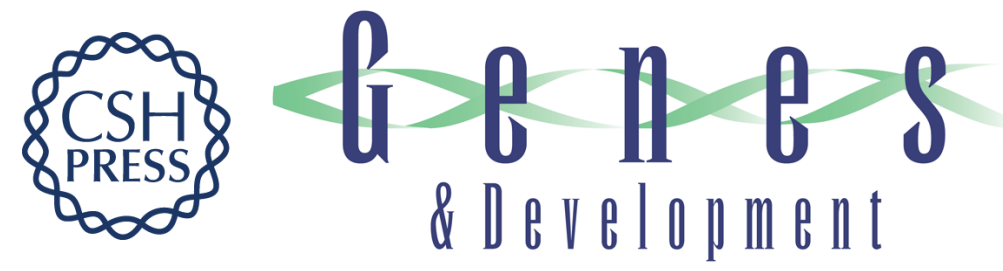

\section{Modeling mutations in the $\mathrm{G}_{1}$ arrest pathway in human gliomas: overexpression of $C D K 4$ but not loss of INK4a-ARF induces hyperploidy in cultured mouse astrocytes}

Eric C. Holland, Wendy P. Hively, Vittorio Gallo, et al.

Genes Dev. 1998, 12:

Access the most recent version at doi:10.1101/gad.12.23.3644

\section{References This article cites 28 articles, 11 of which can be accessed free at: http://genesdev.cshlp.org/content/12/23/3644.full.html\#ref-list-1}

\section{License}

Email Alerting
Service

Receive free email alerts when new articles cite this article - sign up in the box at the top right corner of the article or click here.

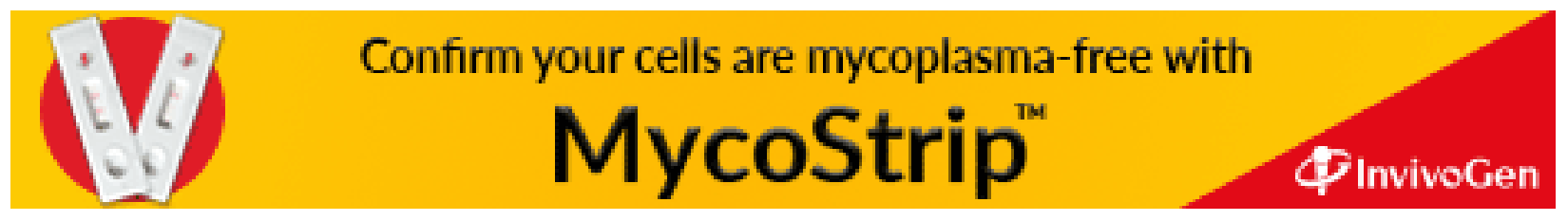

